\title{
UV induced surface modification on improving the cytocompatibility of metallocene polyethylene
}

\author{
SARAVANA K. JAGANATHAN ${ }^{1,2,3}$ and MANI M. PRASATH ${ }^{4}$ \\ ${ }^{1}$ Department for Management of Science and Technology Development, Ton Duc Thang University, Ho Chi Minh City, Vietnam \\ ${ }^{2}$ Faculty of Applied Sciences, Ton Duc Thang University, Ho Chi Minh City, Vietnam \\ ${ }^{3}$ IJN-UTM Cardiovascular Engineering Centre, Department of Clinical Sciences, Faculty \\ of Biosciences and Medical Engineering, Universiti Teknologi Malaysia, \\ 81300 Skudai, Johor, Malaysia \\ ${ }^{4}$ Faculty of Biosciences and Medical Engineering, Universiti Teknologi Malaysia, 81300 Skudai, Johor, Malaysia
}

Manuscript received on September 19, 2017; accepted for publication on December 25, 2017

\begin{abstract}
Demand for medical implants is rising day by day as the world becomes the place for more diseased and older people. Accordingly, in this research, metallocene polyethylene (mPE), a commonly used polymer was treated with UV rays for improving its biocompatibility. Scanning electron microscopy (SEM) images confirmed the formation of crests and troughs, which depicts the improvement of surface roughness of $\mathrm{mPE}$ substrates caused by UV etching. Accordingly, the contact angle measurements revealed that the wettability of $\mathrm{mPE}-2.5 \mathrm{~J} / \mathrm{cm}^{2}\left(68.09^{\circ}\right)$ and $\mathrm{mPE}-5 \mathrm{~J} / \mathrm{cm}^{2}\left(57.93^{\circ}\right)$ samples were found to be increased compared to untreated $\mathrm{mPE}\left(86.84^{\circ}\right)$ indicating better hydrophilicity. Further, the UV treated surface exhibited enhanced blood compatibility as determined in APTT (untreated mPE- $55.3 \pm 2.5 \mathrm{~s}, \mathrm{mPE}-2.5 \mathrm{~J} /$ $\mathrm{cm}^{2}-76.7 \pm 4.1 \mathrm{~s}$ and $\mathrm{mPE}-5 \mathrm{~J} / \mathrm{cm}^{2}-112.3 \pm 2 \mathrm{~s}$ ) and PT (untreated $\mathrm{mPE}-24.7 \pm 1.5 \mathrm{~s}, \mathrm{mPE}-2.5 \mathrm{~J} / \mathrm{cm}^{2}-$ $34.3 \pm 1.1 \mathrm{~s}$ and $\mathrm{mPE}-5 \mathrm{~J} / \mathrm{cm}^{2}-43 \pm 2 \mathrm{~s}$ ) assay. Moreover, the treated $\mathrm{mPE}-2.5 \mathrm{~J} / \mathrm{cm}^{2}(4.88 \%)$ and $\mathrm{mPE}-5$ $\mathrm{J} / \mathrm{cm}^{2}(1.79 \%)$ showed decreased hemolytic percentage compared to untreated $\mathrm{mPE}(15.40 \%)$ indicating better safety to red blood cells. Interestingly, the changes in physicochemical properties of mPE are directly proportional to the dosage of the UV rays. UV modified $\mathrm{mPE}$ surfaces were found to be more compatible as identified through MTT assay, photomicrograph and SEM images of the seeded 3T3 cell population. Hence UV-modified surface of mPE may be successfully exploited for medical implants.
\end{abstract}

Key words: metallocene polyethylene, UV treatment, surface properties, blood compatibility, Cytotoxicity properties, Biocompatible polymers.

\section{INTRODUCTION}

Biomaterials are the promising choice of materials for an extensive range of applications in both diagnostic and therapeutic industries (Hollinger

Correspondence to: Saravana Kumar Jaganathan

E-mail: saravana@tdt.edu.vn
2011, Bhat and Kumar 2013). It has a well-defined reputation in the field of tissue engineering, clinical devices, drug delivery, medical implants, biosensors, cosmetics and food industries (PoncinEpaillard and Legeay 2003, Yoruc and Sener 2012). Hence, the total market value of biomaterial- 
based industries is anticipated to exceed $\$ 88.4$ billion by 2017 from the current value of $\$ 58.1$ billion. Every year, USA alone spend $7-8 \%$ of its total global healthcare outgoings exclusively for biomaterial-related usages (Global materials market). Meanwhile, in coming years the demand for promising biomaterials is anticipated to surge radically due to an increasing number of diseased population. It insinuates the need for more research toward improving the properties of existing materials using simple and feasible modification techniques. So, biomaterials have a significant future in both research and commercial fields.

In general, biomaterials can be classified into three groups based on their origin and applications as (1) synthetic materials, (2) naturally derived, and (3) semisynthetic or hybrid materials. Among the above, synthetic materials like metals, ceramics, polymers and composites are most commonly used for various biomedical applications. The exceptional mechanical properties of metals and their alloys such as tensile strength, elasticity coefficient and fatigue life make them attractive materials for many load-bearing biomedical systems. Some of the examples include wires, screws, etc., to fracture fixation plates and artificial joints. Nevertheless, metallic materials are highly prone to corrosion and tend to release harmful side products in the form of ions, chemical compounds and insoluble components which will cause adverse biological reactions. In the meantime, ceramics emerged as desirable biomaterials because of its captivating bioactive, bioinert and biodegradable properties. They have been used in several applications in the dental field; though the poor mechanical characteristics like brittleness and low strength, made them unsuitable for wide exploitation. Later, polymers gained greater attention than other materials because of their versatility and easy to tailor nature. Presently, polymers are reported to be the most promising type of biomaterials (Jaganathan et al. 2014).
Common biological substances fall under the second category like collagen, heparin, proteins, peptides, carbohydrates, bio-ceramics, etc., are utilized for both surface coating and material synthesis. Though materials completely made of natural substances possess fascinating biocompatible properties they fail in several aspects because of poor physicochemical and mechanical properties. To avoid that complication, natural materials are coupled with synthetic substances and it falls under the third category (Balaji et al. 2015).

The longevity of an implant/biomaterial inside the human body is dependent on its ability to avoid any adverse reaction or damage to the surrounding environment which chiefly relies on the biocompatibility of materials used. But this crucial property is greatly influenced by its physical, chemical, mechanical and biological characteristics. If analyzed deeply, the existence of interconnections between all these essential properties and the durability of a biomaterial can be inferred (John et al. 2015). So, the presence of appropriate surface, mechanical and biological properties will ensure desired function and longevity of an implant. Several methods employing radiation were employed to improve the surface properties and biocompatibility of the polymer. Among them, UV is commonly employed due to its advantages like portability and cost-effectiveness (Jaganathan et al. 2015).

With the growth in the polymer technology, the family of metallocene single-site catalyst produced a new brand of polyolefins and they were reported to have better performance properties like enhanced toughness, sealability, clarity, and elasticity. Metallocene with general formula $M$ $\left(\mathrm{C}_{5} \mathrm{H}_{5}\right)_{2}$ have two cyclopentadienyl anions $(\mathrm{Cp}$, which are attached to the metal center (M) with the oxidation state II. Among these, metallocene polyethylene (mPE) finds wide spread applications in medicine such as syringe tubes, disposable bags, blood bags and storage bottles. Despite $\mathrm{mPE}$ possess excellent permeability to oxygen 
and resistance towards ammonia and water, it suffers lack of blood compatibility to make it ideal candidate for clinical applications (Mohandas et al. 2013). In clinical applications, the assessment of the blood compatibility is one of the main factors which decides the application of the developed biomaterials. When the material contacts with the blood, the first process that occurs is the rapid absorption of plasma proteins which facilitates the platelet surface interaction. The platelet surface interaction might cause the formation of the thrombus which leads to the failure of the developed material (Mao et al. 2004). In this article, UV-induced blood compatibility changes and cytocompatibility of the metallocene polyethylene (mPE) were investigated.

\section{EXPERIMENT DETAILS}

\section{Materials}

The Enable ${ }^{\mathrm{TM}}$ 20-10 Series metallocene polyethylene beads were purchased from ExxonMobil and cast into sheets of $1 \mathrm{~mm}$ thickness at Rubber Technology centre, Indian Institute of Technology, Kharagpur, India. The melt index of mPE is $1.1 \mathrm{~g} / 10$ min and density is about $0.919 \mathrm{~g} / \mathrm{cm}^{3}$. The reagents used in the coagulation assay such as rabbit brain activated cephaloplastin, calcium chloride $(0.025$ M), and thromboplastin (Factor III) were obtained from Diagnostic Enterprises, India. The Roswell Park Memorial Institute medium (RPMI-1640) cell culture medium, fetal bovine serum (FBS), additional sources like sodium pyruvate, nonessential amino acids, L-glutamine, vitamin solution, penicillin and streptomycin were purchased from Life Technologies, Inc., Grand Island, United States.

\section{UV-TREATMENT OF MPE}

Initially, metallocene polyethylene sheet was cut into small square samples of dimensions $1 \mathrm{X} 1$ $\mathrm{cm}^{2}$ and with the thickness of $1 \mathrm{~mm}$. Before UV treatment, the samples were washed with $70 \%$ ethanol followed by rinsing with distilled water to get rid of impurities (if any) presents on the surface. Then, the samples were subjected to two different doses $2.5 \mathrm{~J} / \mathrm{cm}^{2}$ and $5 \mathrm{~J} / \mathrm{cm}^{2}$ respectively. After the completion of UV treatment, the samples were washed with distilled water and dried at room temperature overnight before performing any characterization studies. The untreated sample was named as $\mathrm{mPE}$ whereas the UV treated samples were named as $\mathrm{mPE}-2.5 \mathrm{~J} / \mathrm{cm}^{2}$ and $\mathrm{mPE}-5 \mathrm{~J} / \mathrm{cm}^{2}$.

\section{PHYSICOCHEMICAL CHARACTERISATION}

\section{Contact Angle Assay}

Wettability is an important feature which highly influences the interaction of the material surface with the biological environment in our body. Through the contact angle test, we can infer whether a particular material is hydrophilic or hydrophobic by measuring the angle of water droplet placed on the surface of the sample. Here, the measurement was taken using Dynamic Contact Angle Analyzer (FTA200-First Ten Angstroms). A water droplet of $1 \mu \mathrm{L}$ was used in both cases and the photographs were taken in the ultrafast mode within 30 seconds. Then, the degree of the angle formed was analyzed using a computer interfaced software. The Contact angle experiment was repeated three times using different substrates.

\section{SEM Micrographs}

The SEM micrographs were utilized to illustrate the effect of UV treatment on the mPE surface. For that, $\mathrm{mPE}, \mathrm{mPE}-2.5 \mathrm{~J} / \mathrm{cm}^{2}$ and $\mathrm{mPE}-5 \mathrm{~J} / \mathrm{cm}^{2}$ samples were sputter coated with gold and imaged through Hitachi Tabletop Microscope (TM3000) analysis system, at a magnification of 4000x. At least three images were taken for each sample. 


\section{Coagulation Assays}

The polymer induced abnormalities in the blood clotting cascade were measured by coagulation assays. The onset of fibrin clot was determined by the end-point of these assays once the plateletpoor plasma comes in contact with the control and treated surfaces. The damage to the red blood cells was performed by hemolysis assay.

\section{Prothrombin Test (PT)}

The interdiction of the extrinsic pathway was investigated by the measurement of prothrombin time. To begin the test, $50 \mu \mathrm{L}$ of platelet poor plasma (PPP) incubated at $37^{\circ} \mathrm{C}$ was applied on tested samples followed by adding $50 \mu \mathrm{L}$ of $\mathrm{NaCl}-$ thromboplastin (Factor III) containing $\mathrm{Ca}^{2+}$ ions. Then, the activation of the clot was measured using a stopwatch and a steel hook (Ayyar et al. 2017).

\section{Activated Partial Thromoplastin Test (APTT)}

Similarly, the interdiction of the intrinsic pathway was investigated by the measurement of APTT. To begin the test, the samples to be tested were added to the rabbit brain encephalin and preincubated with $50 \mu \mathrm{L}$ of PPP at $37^{\circ} \mathrm{C}$. Then, the mixture was added to $0.025 \mathrm{M}$ of calcium chloride and the activation of the blood clot was detected using a steel hook and stopwatch (Ayyar et al. 2017).

\section{CYTOCOMPATIBILITY STUDIES}

\section{Hemolysis Test}

The hemolysis assay was performed to investigate the damage to the red blood cells. To begin, the samples to be tested were equilibrated with $0.9 \%$ $\mathrm{w} / \mathrm{v}$ of physiologic saline for $30 \mathrm{~min}$ at $37^{\circ} \mathrm{C}$. Then, the equilibrated silane was added with $3 \mathrm{~mL}$ of diluted blood and incubated for $60 \mathrm{~min}$ at $37^{\circ} \mathrm{C}$. The positive control was the complete hemolysis prepared by mixing blood and distilled water in the ratio of $4: 5$ by volume and the negative control was the physiological saline solution. Then, the mixtures were incubated at $37^{\circ} \mathrm{C}$ for $60 \mathrm{~min}$ and were taken out and centrifuged at $1000 \mathrm{rpm}$ for 5 min. Finally, the absorbance of the supernatant was measured at $542 \mathrm{~nm}$ which represents red blood cell (RBC) damage. The percentage of hemolysis or hemolytic index was calculated as described in previous work (Ayyar et al. 2017).

\section{3-(4,5-Dimethylthiazol-2-Yl)-2,5- \\ Diphenyltetrazolium Bromide (MTT) Assay}

$3 \mathrm{~T} 3$ fibroblast cells were maintained as monolayer cultures in DMEM F-12 supplemented with 10\% fetal calf serum, $1 \%$ glutamine and $1 \%$ each of penicillin and streptomycin. The cells were cultured in a T-25 tissue culture flask for passage and experiments. Before seeding the cultured cells, the untreated and treated mPE samples were cut into small discs and were properly washed with $70 \%$ alcohol and stored in the sterile environment. Then, 3T3 cells were counted $(10,000)$ and seeded on the surface of polymers. Polymer discs seeded with cells were carefully incubated with $5 \% \mathrm{CO}_{2}$ incubator for $24 \mathrm{~h}$. For positive control, Nunc 96-well cell tissue culture plate (Thermo Fischer Scientific, Waltham, MA, USA) was used. After $24 \mathrm{~h}$ incubation, MTT reagent was added to the wells after aspirating the medium. Finally, DMSO was added to dissolve the accumulated dye in the mitochondria to evaluate the percentage viability by measuring the optical density (OD) at $542 \mathrm{~nm}$. $100 \%$ cell viability is the maximum OD under the positive control. Also, photomicrograph pictures are made using an inverted microscope.

\section{Cell Morphology}

The morphology of the seeded 3T3 cells was further examined using SEM. For that, the samples were incubated at $2.5 \%$ glutaraldehyde for $30 \mathrm{mins}$ and washed with PBS for 5 minutes (3 times). The 
samples were dehydrated using serial dilutions of alcohol $(10 \%, 20 \%, 40 \%, 60 \%$ and $80 \%$ respectively). Then, the slides were treated with hexamethyl disilazane (HMDS) for few seconds and gold plated before analyzing using SEM.

\section{Statistical Analysis}

All experiments were conducted thrice independently. Unpaired t-test was used to determine the statistical significance. The results obtained from all experiments are expressed as mean $\pm \mathrm{SD}$. In the case of qualitative experiments, a representative of three images is shown.

\section{RESULTS AND DISCUSSION}

Surface properties of a material play an important role in creating a favourable environment for the cells to regenerate and in averting the damages of blood native components. Biomaterials based researches performed over the years to create better understanding of required properties and its role in controlling the biocompatibility of a material has revealed few essential characteristics. The properties such as surface wettability, energy, roughness charge, chemistry, and reactivity are identified to be most important. And to attain better biocompatibility, a material should possess above characters to some appropriate extent (Anderson et al. 2001). Among various properties, the surface roughness is a vital factor which greatly determines the material relationship with biomolecules and biological environment. Previous studies have reported that surfaces with better roughness will greatly encourage cell adhesion, proliferation and migration in both in vitro and in vivo conditions. Moreover, the micro-rough surfaces were noted to stimulate cells for further differentiation and modulates the biological response of tissues in contact when compared to smooth surfaces. However, the extent of roughness varied depends on the application, for instance, large cells like osteoblasts were reported to proliferate better on surfaces with roughness in micro levels. In contrast, for neural and endothelial cells regeneration nanoscale roughness was noted to be more suitable. (Chang and Wang 2011, Vagaska et al. 2010, Kim et al. 2007).

\section{SEM ANALYSIS}

To demonstrate the presence of required roughness, the SEM micrographs recorded. Fig. 1 clearly shows the formation of pits in $\mathrm{mPE}-2.5 \mathrm{~J} / \mathrm{cm}^{2}$ when compared to the untreated $\mathrm{mPE}$ because of the etching of polymer surface by the UV rays. Whilst, the quantity and size of the pits observed to increase in $\mathrm{mPE}-5 \mathrm{~J} / \mathrm{cm}^{2}$ substrates because of prolonged etching. Therefore, the characteristic changes visibly express a significant increase in surface a

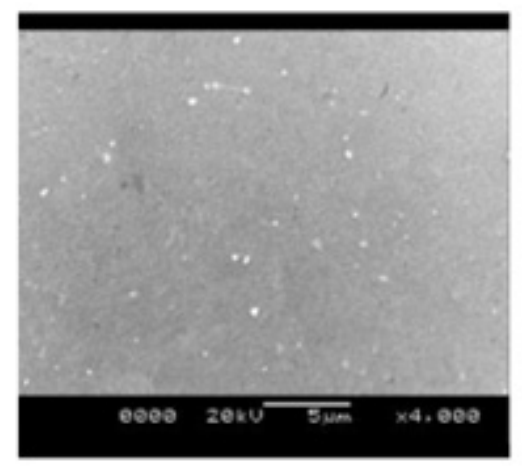

b

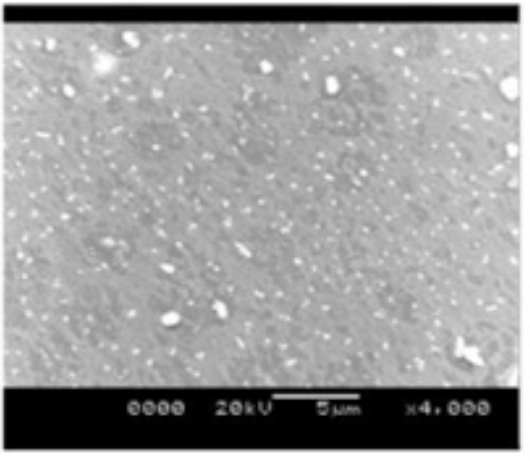

C

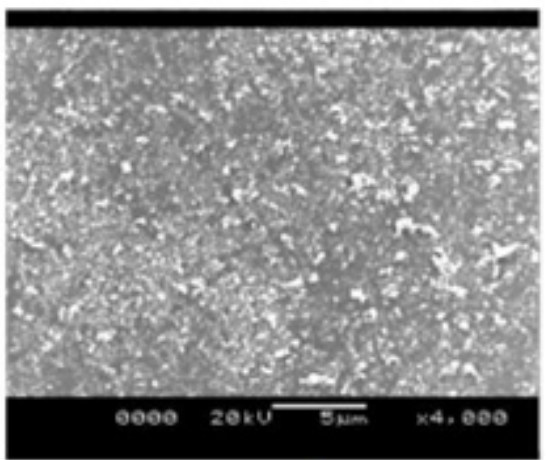

Figure 1 - Representative SEM images of the a) $\mathrm{mPE}$, b) $\mathrm{mPE}-2.5 \mathrm{~J} / \mathrm{cm}^{2}$ and c) $\mathrm{mPE}-5 \mathrm{~J} / \mathrm{cm}^{2}$ treated samples. 
roughness of mPE samples after UV treatment. So, the surface modified samples are anticipated to establish a platform for friendly relation with biological substances.

\section{WETTABILITY}

Despite surface roughness, wettability is also an important surface parameter which plays a pivotal role in controlling biomolecule adsorption and cellular interaction. In general, a substrate with less wettability and low surface energy interacts poorly with a native environment which often results

TABLE I

Mean contact angles of the $\mathrm{mPE}, \mathrm{mPE}-2.5 \mathrm{~J} / \mathrm{cm}^{2}$ and mPE-5 J/cm ${ }^{2}$ treated samples (*mean differences were significant compared with untreated mPE $(\mathbf{p}<0.05))$.

\begin{tabular}{ccc}
\hline S.No & Samples & $\begin{array}{c}\text { Contact angle } \\
(\text { mean } \pm \text { SD) }\end{array}$ \\
\hline 1 & $\begin{array}{c}\text { Control } \\
\text { (untreated } \mathrm{mPE})\end{array}$ & $86.84 \pm 1.65$ \\
2 & $\mathrm{mPE}-2.5 \mathrm{~J} / \mathrm{c}^{\mathrm{m}} 2$ & $68.09 \pm 0.94^{*}$ \\
3 & $\mathrm{mPE}-5 \mathrm{~J} / \mathrm{cm}^{2}$ & $57.93 \pm 2.05^{*}$ \\
\hline
\end{tabular}

$\mathbf{a}$

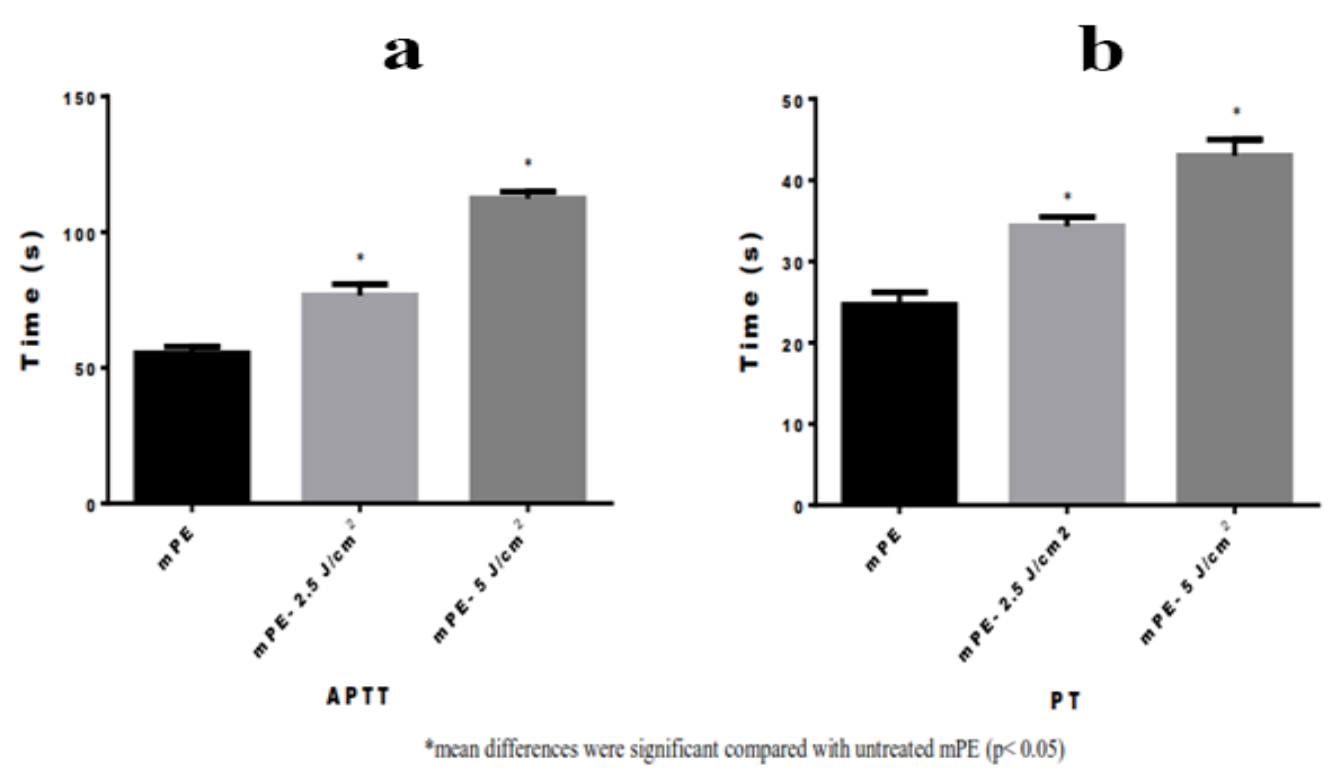

in the activation and aggregation of undesired biomolecules. In this study, the mean contact angle of P-mPE was calculated as $86.84^{\circ}$, whereas in $\mathrm{mPE}-2.5 \mathrm{~J} / \mathrm{cm}^{2}$ and $\mathrm{mPE}-5 \mathrm{~J} / \mathrm{cm}^{2}$ samples it was reduced to $68.09^{\circ}$ and $57.93^{\circ}$ respectively as shown in Table I. So, from the results, we can clearly infer that after UV treatment the mPE surfaces become hydrophilic because the contact angle recorded is well below $70^{\circ}$. Basically, the hydrophilic surfaces are reported to facilitate the bioadhesion, i.e., formation of uniform biofilm. This property is particularly important in long-term implants such as cardiovascular and orthopaedic grafts since it is reported to enhance cells incorporation and biomechanical characteristics (Jaganathan et al. 2014, Maitz et al. 2015).

\section{COAGULATION ASSAYS}

Blood coagulation assays of the surface treated samples were indicated in the Fig. 2a, b. It was observed that the both PT and APTT time of treated samples were observed to be enhanced

Figure 2 - a) APTT and b) PT assessment of mPE, mPE-2.5 J/cm ${ }^{2}$ and $\mathrm{mPE}-5 \mathrm{~J} / \mathrm{cm}^{2}$ treated samples. The mean of the $\mathrm{mPE}$ and $\mathrm{mPE}-2.5 \mathrm{~J} / \mathrm{cm}^{2}$ and $\mathrm{mPE}-5 \mathrm{~J} / \mathrm{cm}^{2}$ treated samples along with their standard deviation is indicated from three individual experiments. Further mean differences between the mPE and the mPE-2.5 $\mathrm{J} / \mathrm{cm}^{2}$ and $\mathrm{mPE}-5 \mathrm{~J} / \mathrm{cm}^{2}$ treated samples were significant $(\mathrm{p}<0.5)$. 
when compared with the untreated surface. The APTT of $\mathrm{mPE}-2.5 \mathrm{~J} / \mathrm{cm}^{2}$ and $\mathrm{mPE}-5 \mathrm{~J} / \mathrm{cm}^{2}$ treated samples were found to be $76.7 \pm 4.1 \mathrm{~s}$ and 112.3 $\pm 2 \mathrm{~s}$ and for the untreated surface, the APPT time was observed to be only $55.3 \pm 2.5 \mathrm{~s}$ as shown in Fig. 2a. Similarly, the value of PT for mPE$2.5 \mathrm{~J} / \mathrm{cm}^{2}$ and $\mathrm{mPE}-5 \mathrm{~J} / \mathrm{cm}^{2}$ treated samples were observed to be $34.3 \pm 1.1 \mathrm{~s}$ and $43 \pm 2 \mathrm{~s}$ and for the untreated surfaces, the value of PT was found to be $24.7 \pm 1.5 \mathrm{~s}$ as shown in Fig. 2b. In the recent study, Mohandas et al investigated the effect of microwave induced surface modification of mPE. Their results showed enhanced blood compatibility and of mPE and they ascribed it to the improved physicochemical properties like wettability and surface roughness (Mohandas et al. 2013). In this work, it was observed an increase in wettability and improved surface roughness and hence, the improved blood compatibility of UV- treated surface samples must be linked to its improved physicochemical properties.

\section{CYTOCOMPATIBILITY STUDIES}

The surfaces with higher wettability allow the displacement of undesired plasma proteins (like fibrinogen) by cell adhesive serum proteins, such as fibronectin and vitronectin, due to proteinspecific affinity (Balaji et al. 2015). This property of controlling and translating protein adsorption is greatly needed to avoid the complication of blood component activation. Moreover, the obtained contact angle falls in the optimum range of $70^{\circ}-30^{\circ}$ which has previously been reported to be suitable for regeneration of cells like fibroblasts, HUVECs, osteoblasts and cardiomyocytes (Anderson 2001). The above discussed effect of improved surface roughness and wettability was clearly observed in the cytocompatibility tests. The hemolysis assay of the surface treated samples are indicated in Fig. 3. The results of hemolysis assay showed that untreated sample exhibited $15.40 \%$ hemolysis, whereas, the surface showed only treated samples $\mathrm{mPE}-2.5 \mathrm{~J} / \mathrm{cm}^{2}$ and $\mathrm{mPE}-5 \mathrm{~J} / \mathrm{cm}^{2}$ showed $4.88 \%$ and $1.79 \%$ hemolysis. It was clearly evident that the treated surfaces showed decreased hemolytic index indicating high safety to red blood cells. Further, MTT assay showed that the cultured 3T3 cells adhered well on the UV treated surface when compared to untreated mPE as shown in Fig. 4a, b. The mean percentage cell viability of the untreated surface was found to be 15.67. The treated mPE$2.5 \mathrm{~J} / \mathrm{cm}^{2}$ and $\mathrm{mPE}-5 \mathrm{~J} / \mathrm{cm}^{2}$ samples expressed a cell viability percentage of 70.67 and 91 respectively as shown in Fig. 4a. In the photomicrographs on $\mathrm{mPE}-5 \mathrm{~J} / \mathrm{cm}^{2}$ surface, the cells seem to adhere at a much higher rate as shown in Fig. 4b. Moreover, the presence of spindle structure indicates a suitable environment for the proliferation of the 3T3 cells (Zhou et al. 2016). Further, it is also evident from the SEM images that the cells seeded on the modified surface are more viable than on untreated samples as shown in Fig. 5. It was observed that the mPE-2.5 $\mathrm{J} / \mathrm{cm}^{2}$ treated $\mathrm{mPE}$ seems to be non-toxic surface, whereas, mPE-5 J/cm² treated mPE displayed similar cell viability percentage as the tissue

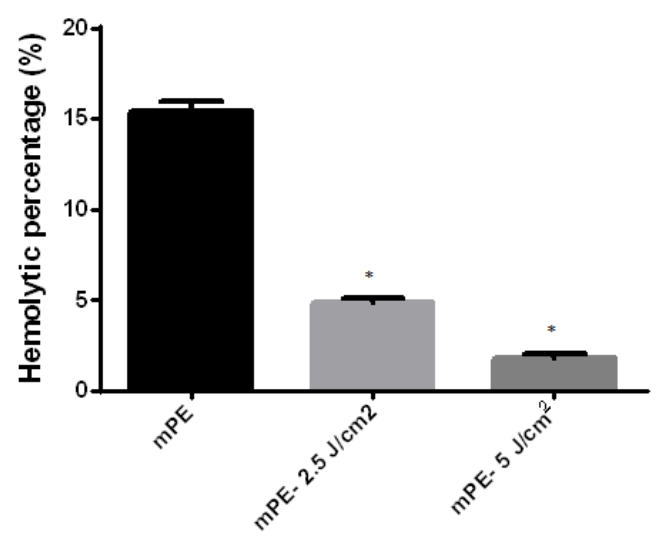

*mean differences were significant compared with untreated $\mathrm{mPE}(\mathrm{p}<0.05)$.

Figure 3 - Hemolysis assay of $\mathrm{mPE}, \mathrm{mPE}-2.5 \mathrm{~J} / \mathrm{cm}^{2}$ and $\mathrm{mPE}-$ $5 \mathrm{~J} / \mathrm{cm}^{2}$ treated samples. The mean of the $\mathrm{mPE}$ and $\mathrm{mPE}-2.5 \mathrm{~J} /$ $\mathrm{cm}^{2}$ and $\mathrm{mPE}-5 \mathrm{~J} / \mathrm{cm}^{2}$ treated samples along with their standard deviation is indicated from three individual experiments. Further mean differences between the mPE and the mPE-2.5 J/ $\mathrm{cm}^{2}$ and $\mathrm{mPE}-5 \mathrm{~J} / \mathrm{cm}^{2}$ treated samples were significant $(\mathrm{p}<0.5)$. 
a

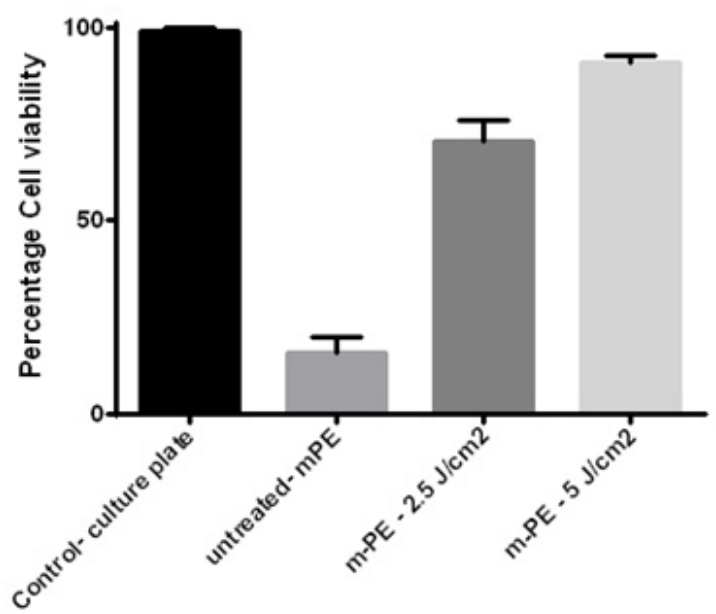

b

A

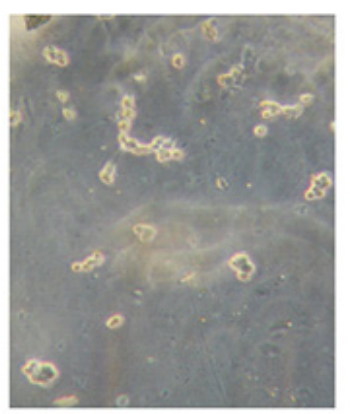

B

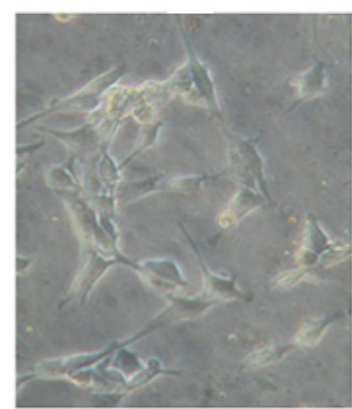

C

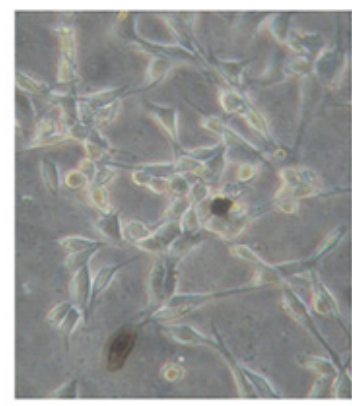

Figure 4 - (a) Cell viability of $\mathrm{mPE}, \mathrm{mPE}-2.5 \mathrm{~J} / \mathrm{cm}^{2}$ and $\mathrm{mPE}-5 \mathrm{~J} / \mathrm{cm}^{2}$ treated samples after $24 \mathrm{~h}$ using MTT assay (b) Photomicrograph of the $\mathrm{mPE}, \mathrm{mPE}-2.5 \mathrm{~J} / \mathrm{cm}^{2}$ and $\mathrm{mPE}-5 \mathrm{~J} / \mathrm{cm}^{2}$ treated samples seeded with $3 \mathrm{~T} 3$ fibroblast cells after $24 \mathrm{~h}$. The mean of the $\mathrm{mPE}$ and $\mathrm{mPE}-$ $2.5 \mathrm{~J} / \mathrm{cm}^{2}$ and $\mathrm{mPE}-5 \mathrm{~J} / \mathrm{cm}^{2}$ treated samples along with their standard deviation is indicated from three individual experiments.

culture plates. The commercial polymers used for manufacturing the cell culture plates were styrene and propylene (Coassin et al. 2001). Generally, they are hydrophobic which limits the cell adherence and proliferation (Dowling et al. 2011). To improve the cell adherence and proliferation, the biocoatings with variety of surface treatment were utilized to improve the hydrophilic nature in order to enhance the cell adherence and proliferation (Mandracci et al. 2016). In our study, the UV treated mPE improved the hydrophilic nature which facilitates the enhanced cell adherence and proliferations. Further, the UV treatment was cost effective and the UV treated mPE might be used as an alternate candidate for the manufacturing of the cell culture plates.

\section{CONCLUSIONS}

Technologies existing in this modern era paves a way for the exploration of several advanced materials, however, the availability of those materials for medical use will take a few decades of time as it has to undergo a series of clinical trials. So, in addition to discovering new substitutes, more researches need to be carried out on improving the quality of materials which have been utilized for 
a

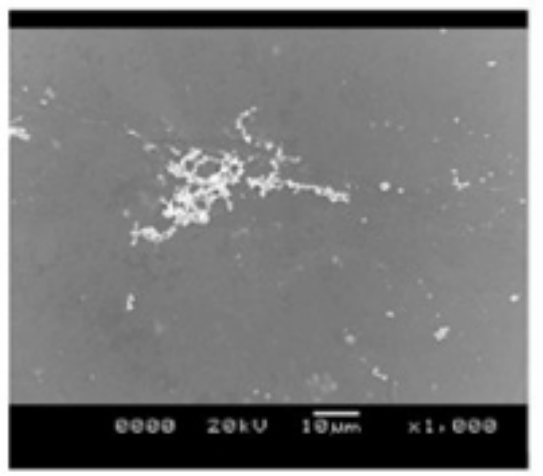

b

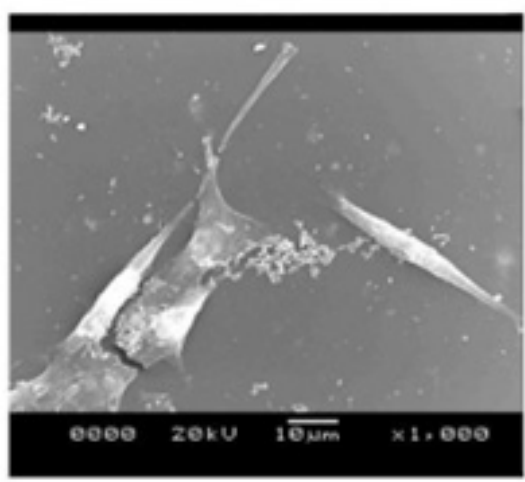

C

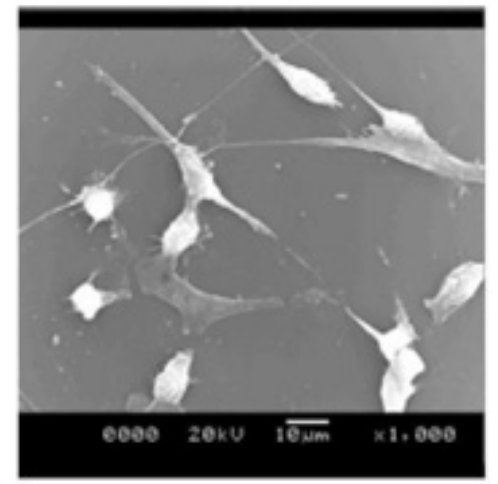

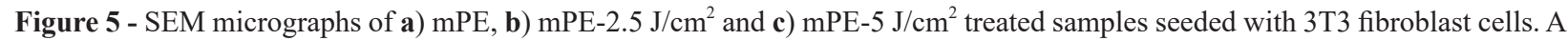
representative image of three individual experiments is shown.

various medical applications. This not only ensures timely implementation of the resultant product for clinical usage, but also help us to combat the future demand for reliable and cost-effective implants. Hence, this work shows that following UV treatment, the surface roughness, wettability and blood compatibility of mPE samples enhanced notably which also depended on the UV dose. The cytocompatibility of mPE also improved as evidently seen from the photomicrograph and SEM images. The improved blood compatibility of the UV exposed mPE may be utilized for blood contacting devices. Further, the cell viability results of $\mathrm{mPE}-5 \mathrm{~J} / \mathrm{cm}^{2}$ was similar with the existing cell culture plates. Hence, it might be a plausible candidate for manufacturing the cell culture plates. However, it has to be further validated in other cell lines and animal model to justify its proposed applications.

\section{ACKNOWLEDGMENTS}

This work was supported by the Ministry of Higher Education Malaysia with the Grant no. Q.J130000.2545.17H00.

\section{REFERENCES}

ANDERSON JM. 2001. Biological responses to materials. Annual Rev Mater Res 31(1): 81-110.

AYYAR M, MANI MP, JAGANATHAN SK AND RATHANASAMY R. 2017. Preparation, characterization and blood compatibility assessment of a novel electrospun nanocomposite comprising polyurethane and ayurvedicindhulekha oil for tissue engineering applications. Biomed Eng/Biomedizinische Technik: 1-9.

BALAJI A, JAGANATHAN SK, VELLAYAPPAN MV, JOHN AA, SUBRAMANIAN AP, SELVAKUMAR M, MOHANDAS H AND SUPRIYANTO E. 2015. Prospects of common biomolecules as coating substances for polymeric biomaterials. RSC Adv 5(85): 69660-69779.

BHAT S AND KUMAR A. 2013. Biomaterials and bioengineering tomorrow's healthcare. Biomater 3(3): e24717.

CHANG HI AND WANG Y. 2011. Cells and Biomaterials Cell Responses to Surface and Architecture of Tissue Engineering Scaffolds. Regenerative Medicine and Tissue Engineering, Intech Publications, 27 p.

COASSIN PJ, HAROOTUNIAN AT, TSIEN RY AND PHAM AA. 2001. Inventors; Aurora Biosciences Corporation, assignee. Low background multi-well plates with greater than 864 wells for spectroscopic measurements. United States patent US 6: 229-603.

DOWLING DP, MILLER IS, ARDHAOUI M AND GALLAGHER WM. 2011. Effect of surface wettability and topography on the adhesion of osteosarcoma cells on plasma-modified polystyrene. J Biomater App 26(3): 327 347.

HOLLINGER JO. 2011. An Introduction to Biomaterials. CRC Press, $2^{\text {nd }}$ ed., 644 p. http://www.marketsandmarkets.com/ 
PressReleases/globalbiomaterials-market-worth-US58.1Billion-by-2014.asp.

JAGANATHAN SK, SUPRIYANTO E, SELVAKUMAR M, BALAJI A AND ASOKAN MK. 2014. Biomaterials in Cardiovascular Research: Applications and Clinical Implications. BioMed Res Int: 1-11.

JAGANATHAN SK, BALAJI A, VELLAYAPPAN MV, SUBRAMANIAN AP, JOHN AA, ASOKAN MK AND SUPRIYANTO E. 2015. Radiation-induced surface modification of polymers for biomaterial application. J Mater Sci 50(5): 2007-2018.

JOHN AA, SUBRAMANIAN AP, VELLAYAPPAN MV, BALAJI A, JAGANATHAN SK, MOHANDAS H, PARAMALINGGAM T, SUPRIYANTO E AND YUSOF M. 2015. Physico-chemical modification as a versatile strategy for the biocompatibility enhancement of biomaterials. RSC Adv 5(49): 39232-39244.

KIM MH, KINO-OKA M, KAWASE M, YAGI K AND TAYA M. 2007. Response of human epithelial cells to culture surfaces with varied roughnesses prepared by immobilizing dendrimers with/without d-glucose display. J Biosci Bioeng 103(2): 192-199.

MAITZ MF. 2015. Applications of synthetic polymers in clinical medicine. Biosurf Biotribol 1(3): 161-176.
MANDRACCI P, MUSSANO F, RIVOLO P AND CAROSSA

S. 2016. Surface treatments and functional coatings for biocompatibility improvement and bacterial adhesion reduction in dental implantology. Coatings 6(1): 1-22.

MAO C, QIU Y, SANG H, MEI H, ZHU A, SHEN J AND LIN S. 2004. Various approaches to modify biomaterial surfaces for improving hemocompatibility. Advances in colloid and interface science. 110(1): 5-17.

MOHANDAS H, SIVAKUMAR G, KASI P, JAGANATHAN SK AND SUPRIYANTO E. 2013. Microwave-assisted surface modification of metallocene polyethylene for improving blood compatibility. BioMed Res Int 253473 1-7.

PONCIN-EPAILLARD FA AND LEGEAY G. 2003. Surface engineering of biomaterials with plasma techniques. J Biomater Sci Polym Ed 14(10): 1005-1028.

VAGASKA BA, BACAKOVA L, FILOVA EL AND BALIK KA. 2010. Osteogenic cells on bio-inspired materials for bone tissue engineering. Physiol Res 59(3): 309-322.

YORUC ABH AND SENER BC. 2012. Biomaterials, A Roadmap of Biomedical Engineers and Milestones. Intech Publications, p. 1-240.

ZHOU Q, YANG P, LI X, LIU H AND GE S. 2016. Bioactivity of periodontal ligament stem cells on sodium titanate coated with graphene oxide. Sci Rep 6: 1-10. 